\title{
Long-term survival from adenocarcinoma of the esophagus after transthoracic and transhiatal esophagectomy
}

Kjell K Ovrebo ${ }^{1,2^{*}}$, Stein A Lie ${ }^{2,3}$, Ole D Laerum ${ }^{4}$, Knut Svanes ${ }^{1,2}$ and Asgaut Viste ${ }^{1,2}$

\begin{abstract}
Background: The effects of transthoracic or transhiatal esophagectomy on the long-term survival of patients who had adenocarcinoma of the esophagus were compared, as were factors applicable in preoperative stratification of patient treatment.

Methods: A cohort of 147 consecutive patients with adenocarcinoma of the esophagus was evaluated for esophagectomy between 1984 and 2000. The patients were followed prospectively and observed survival rates of patients with a transthoracic or transhiatal approach to esophagectomy were compared by standardized mortality ratio (SMR) and relative mortality ratio (RMR) using the expected survival of a matched Norwegian population.
\end{abstract}

Results: A R0 resection was performed by transthoracic $(n=33)$ or a transhiatal $(n=55)$ esophagectomy in $88(60 \%)$ patients with a median age of 61 (range: $35-77)$ and $70(42-88)$ years, respectively $(P<0.001)$. Tumor stages and other possible risk factors were similar in the two groups. Transthoracic or transhiatal esophagectomy resulted in a median survival time of 20.5 (95\% confidence interval (Cl): 10.4-57.6) and 16.4 (10.6-28.7) months, respectively. The respective survival rates were $31.2 \%$ and $27.8 \%$ by 5 years, and $21.3 \%$ and $16.6 \%$ by 10 years with an overall RMR of $1.14(P=0.63)$. Median survival time in the absence or presence of lymph node metastases was 74.0 (95\% Cl: 17.5-166.4) and 10.7 (7.9-14.9) months. The corresponding survival rates by 10 years with non-involved or involved nodes were $48.9 \%$ and $3.8 \%$ respectively (RMR 2.22, $P=0.007$ ). Patients with a pT1-tumor were few and the survival rate was not very different from that of the general population ( $S M R=1.7,95 \% \mathrm{Cl}$ : $0.7-4.1$ ). The median survival time of patients with a pT2-tumor was 30.4 (95\% Cl: 9.0-142) months and with a pT3-tumor 14 (9.2-16.4) months. The survival rates by 10 years among patients with a pT1 tumor were $57.0 \%$ (95\% Cl: 14.9-78.9), pT2 33.3\% (11.8-52.2), and pT3 7.1\% (1.9-15.5). The relative mortality for T3 stages compared to T1 stages was statistically significant $(\mathrm{RMR}=3.22, P=0.024)$.

Conclusion: Transthoracic and transhiatal esophagectomy are both effective approaches for treatment of adenocarcinoma of the esophagus and survival of more than 10 years can be expected without adjuvant chemotherapy. However, increasing depth of tumor invasion and lymph node metastases reduce life expectancy.

\section{Background}

Adenocarcinoma of the lower esophagus and the gastroesophageal (GE) junction represent an increasing health problem. In 2005 there were on a worldwide basis nearly half a million new cases and, due to an extremely bad prognosis, almost as many deaths. Once an invasive adenocarcinoma has developed, the diagnosis is usually

\footnotetext{
* Correspondence: kkovrebo@gmail.com

'Department of Surgery, Haukeland University Hospital, Bergen 5021, Norway

${ }^{2}$ Department of Surgical Sciences, University of Bergen, Bergen, Norway

Full list of author information is available at the end of the article
}

made at a stage where the disease is already advanced. In Europe and the USA there has been an almost sixfold increase in the incidence of these tumors from 1975 to 2000 , and this increase seems to continue [1,2].

Although surgery dominates the treatment of local disease, comparative studies between different surgical approaches are few and controversies still exists on the extent of esophagus resection, lymph node dissection and preferred fields of dissection [3]. Transthoracic esophagectomy is reported with superior survival rates compared with transhiatal esophagectomy [4-7], but the

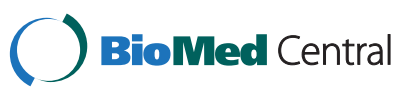


opposite has also been reported [8]. A Dutch trial could not identify any statistical significant difference between the survival rates of patients subject to transthoracic esophagectomy with extended en bloc lymph node resection or transhiatal esophagectomy with limited abdominal lymph node dissection $[9,10]$. Other reports indicate that gastrectomy with partial esophagectomy and transhiatal esophagectomy for cardiac cancers obtain similar survival rates [11-14]. Minimal invasive approaches to esophagectomy have increased exponentially in England, but mortality rates and length of stay is similar to that of patients treated with conventional surgery [15].

The precision in localization of adenocarcinoma in the distal esophagus may vary and reports on epidemiology and surgical treatment are therefore difficult to evaluate. The Siewert's classification improved the differentiation and the precision in reports on these tumors and the classification may serve as a base for selection among different surgical approaches [16]. Similar support for treatment algorithms are not necessarily found in the seventh edition of TNM classification [17]. Most studies, however, include patients with both Siewert type I and type II cardiac cancers. When focusing on type I cardiac or distal esophagus adenocarcinoma, survival rates obtained by transthoracic esophagectomy appear superior to that by transhiatal esophagectomy [10]. The diversity of surgical approaches and survival benefit of patients subjected to esophagectomy for adenocarcinoma of the distal esophagus suggest that further studies are needed in order to establish the preferred surgical approach before the addition of different types of multimodal therapy confound evaluation of the surgical approaches.

This study was performed in order to compare the long-term results of transthoracic or transhiatal esophagectomy among patients with type I adenocarcinoma of the esophagus. These patients were all operated before the introduction of multimodal radiochemotherapy.

In order to adjust for all possible demographic confounders that could distort the results and the survival analyses, patient survival was compared with and adjusted for population mortality rates.

\section{Methods}

In the period 1984-2000, 147 consecutive patients with adenocarcinoma of the distal esophagus were evaluated for surgery in this referral center for patients with carcinoma of the esophagus in Western Norway. Patients were registered and followed prospectively.

Distant metastases or poor health obviated a curative resection in $33(22 \%)$ of the patients. Another 26 (18\%) patients received an esophagectomy but distant metastases or involved margins of a locally advanced tumor were identified late during the operation implying residual tumor tissue in the patient after resection (R2-resection). This is a prospective study of the remaining 88 (60\%) patients subjected to a R0 resection for adenocarcinoma of the esophagus. The patients were not offered adjuvant or neoadjuvant radiochemotherapy. The median time of postoperative observation was 16 (range 0-203) months. Patients subject to a transthoracic or a transhiatal resection were observed for a median of 20 (range 3-203) and 16 (range 0-157) months, respectively.

\section{Staging}

All patients were evaluated by endoscopy. Tumors at or close to the GE junction were classified as adenocarcinoma of the esophagus if the tumor was not visible at the cardia with the endoscope looped or inverted in the stomach. Siewert's classification [16] of tumors at the GE junction has been introduced, but patients are still offered esophagectomy for tumors invisible at the cardia when inspected from the stomach with a looped endoscope. Preoperative endoscopic ultrasonography (EUS) was introduced for staging of all patients with carcinoma of the esophagus in this department from 1991 [18]. Computed tomography (CT) of the chest and abdomen as well as ultrasonography of the liver and chest radiographs were used for identification of distant metastases. Invasion of the tumor into adjacent organs (Stage III, T4, any N, any M) or distant metastases (Stage IV B) precluded surgery. Surgery was also prohibited among patients with severe symptomatic heart or lung disease, poor general health or cerebral dysfunction.

\section{Surgical procedures}

Esophagectomy was performed with a transhiatal or a transthoracic approach. The surgical approach was determined by patient comorbidity and the surgeons preferred technique.

The transhiatal approach was performed according to Orringer $[5,19]$ with an upper abdominal midline and a left cervical incision. A generous incision of the esophageal hiatus allowed dissection in the lower mediastinum with circumferential removal of the fat pad in the lower mediastinum followed by blunt dissection of the oral esophagus from the esophageal hiatus and thoracic inlet $[5,19]$.

The transthoracic procedure was performed with the patient in a left lateral position, and a right posterolateral thoracotomy in the fifth or sixth intercostal space. Dissection of the esophagus in the thorax involved en bloc removal of the esophagus, with covering pleura, and all tissue surrounding the esophagus according to Akiyama [20]. The aorta, tracheal membrane and the pericardia served as margin for the dissection and the contralateral pleura was resected as left lateral margin caudal to the pulmonary veins. The azygos vein was 
routinely divided in the upper mediastinum, but preserved as the dissection was carried out medial to the ascending vein. The thoracic duct was routinely dissected, ligated, and divided at the level of the diaphragm. Lymph nodes in the aorta-pulmonary window were dissected. The bronchial branches of the vagal nerve were preserved. The esophagus was divided orally to the crossing azygos vein and the oral part of the esophagus was dissected into the neck. The patient was later rotated into a supine position for the abdominal and neck dissections.

Both the transhiatal and the transthoracic approach involved extensive lymph node dissection in the upper abdomen and in the lower mediastinum. Tissue and lymph nodes along the common hepatic artery, the celiac trunk and along the top of the pancreas and splenetic artery to the spleen were removed en bloc with lymph nodes along the lesser curve of the stomach, the cardia and the specimen. Lymph nodes were not dissected in the neck.

The left gastric artery was divided at the celiac trunk. The right epiploic arcade and the right gastric artery were carefully preserved. The spleen was removed in patients operated during the 1980 s but preserved during the last decade unless its removal was dictated by bleeding.

The esophagus was substituted by a stomach tube in 83 cases. The tube was approximately $5 \mathrm{~cm}$ in diameter and created prior to lymph node dissection, by firing a linear stapler several times along the greater curve of the stomach from the angle at the lesser curve to the top of the fundus. Pyloroplasty was not performed routinely, but a Kocher's maneuver was added in order to improve the reach of the tube. The left colon was used as esophageal substitute in five patients due to former gastric surgery. In all cases the esophageal substitute was pulled up through the posterior mediastinum. The cervical esophagus was approached from the left side of the neck for the anastomosis in all but two patients in whom the anastomosis was performed within the thorax. The cervical anastomosis was constructed with a two-layer Vicryl 3-0, (Ethicon, Norderstedt, Germany) interrupted stitches, a running PDS 4-0 (Ethicon, Norderstedt, Germany) singlelayer technique or a circular stapling instrument according to the individual operator's preferences.

\section{Postoperative follow up}

The patients were observed in a recovery unit until ventilation was adequate and thereafter in a regular ward. The pleural tubes were removed when fluid leakage was less than $100 \mathrm{ml}$ per day. Enteral nutrition was supplied by a transabdominal jejunal catheter from day one and the patients were allowed oral feeding according to their own preferences. Water-soluble oral contrast study
(Omnipaque) or endoscopy was performed on suspicion of dehiscence of the anastomosis.

The specimens entered a routine formaldehyde fixation, hematoxylin staining and histopathological evaluation at the department of pathology. No special fat clearance or staining techniques were employed. The stage of disease was classified according to the Union for International Cancer Control's TNM classification of malignant tumors in the esophagus (sixth edition) [21].

The patients were followed prospectively at the outpatient clinic every 6 months for 2 years, and then once a year for 5 years or until death intervened. Patients referred from other hospitals were followed at their respective hospitals. A few patients were accepted for palliative chemotherapy upon recurrence of disease.

The project was approved by the Regional Committees for Medical and Health Research Ethics (REK 053228) and in addition by the Norwegian Directorate of Health according to the national legislation for biobanks. The investigation was performed according to the World Medical Association Declaration of Helsinki and approved by the Norwegian Social Science Data Services.

\section{Statistics}

The SPSS statistical package version 17 (SPSS Inc, Chicago, USA) was used for the descriptive analyses. The independent sample $t$-tests assessed differences between groups, and non-parametric Mann-tests (Whitney U-test) were used when outliers affected the analyses significantly. Chi-square tests were used to compare categorical data or Fisher exact test when the expected number in any cell of the contingency tables was less than five.

Observed patient survival rates were obtained by the Kaplan-Meier method and presented at $5\left(\mathrm{~S}_{\mathrm{O}} 5\right)$ and 10 $\left(\mathrm{S}_{\mathrm{O}} 10\right)$ years with $95 \%$ confidence limits. Median time of survival was calculated and presented with $95 \%$ confidence interval (CI). The observed survival curves were compared with expected survival curves calculated from mortality rates, available in 1-year intervals (age and calendar year) for both genders and all birth cohorts, obtained from Statistics Norway [22]. The expected curves reflect thus the survival curves of the Norwegian population with the corresponding composition of gender, age, and year of birth to that of the study group (Expected number of deaths, Exp) as the patients [23].

The standardized mortality ratio (SMR) was used to compare the observed to the expected mortality. The SMR is the ratio of the observed patient mortality and the mortality in the Norwegian population with the same composition of gender, age, and year of birth as that of the study group [24].

In order to compare the SMR of the different covariates (gender, age, stage of disease, surgical approach) a 
modified Cox-model for time-dependent covariates was fitted [25].

This model includes population mortality rates and adjustment for potential confounders (such as gender, age, stage of disease, surgical approach). The quantities estimated in this model are referred to as relative mortality ratios (RMR). The RMRs (including the 95\% CIs) compares the SMRs for the different levels of the variables. In an unadjusted model, the RMR will be almost identical to the SMR of one of the covariates divided by the SMR of the reference category (e.g. $R M R_{\text {Gender }}=S M R_{\text {Female }} / S M R_{\text {Male }}$ ). The analyses were performed with custom and premade Fortran programs [23,25]. Results are presented as means or median, and with $95 \% \mathrm{CIs}$ or range according to appropriate parametric or nonparametric analyses. A $P$ value of less than 0.05 was considered statistically significant.

\section{Results}

The median age of the 88 patients with a $\mathrm{R} 0$ resection was 67 (range: 35-88) years and the median age of patients with transthoracic $(n=33)$ or transhiatal $(n=55)$ resection was 61 (range: $35-77)$ and $70(42-88)$ years, respectively $(P<0.001)$. Men and women were represented in both treatment groups, but males (75) outnumbered females (13) in this series of patients. Clinically important comorbidity was present among $36 \%$ of the patients. Table 1 summarizes the characteristics of the patients in the two treatment groups.

Of the patients with a transthoracic procedure $64 \%$ experienced complications and $51 \%$ of patients with a transhiatal procedure experienced complications $(P=0.152)$, and some patients experienced several complications (Table 2). Adverse events during the surgical procedure occurred among $13 \%$ of the patients. Postoperative complications were dominated by infectious diseases

\begin{tabular}{|c|c|c|c|c|}
\hline & $\begin{array}{c}\text { All } \\
n=88\end{array}$ & $\begin{array}{c}\text { Transthoracic } \\
n=33\end{array}$ & $\begin{array}{c}\text { Transhiatal } \\
n=55\end{array}$ & $P$ \\
\hline \multicolumn{5}{|l|}{ Gender } \\
\hline females:males & $13: 75$ & $7: 26$ & $6: 49$ & 0.222 \\
\hline Age (years) & $67(35-88)$ & $61(35-77)$ & $70(42-88)$ & 0.001 \\
\hline Observation (months) & $16(0-203)$ & $20(3-203)$ & $16(0-157)$ & 0.179 \\
\hline \multicolumn{5}{|l|}{ Comorbidity } \\
\hline Cardiac & $18(20)$ & $4(12)$ & $14(25)$ & 0.177 \\
\hline Pulmonary & $12(14)$ & $2(6)$ & $10(18)$ & 0.195 \\
\hline Diabetes mellitus & $7(8)$ & $2(6)$ & $5(9)$ & 0.698 \\
\hline Total & $32(36)$ & $9(27)$ & $23(42)$ & 0.252 \\
\hline
\end{tabular}

(43\%), of which pneumonia (34\%) was most frequent; $14 \%$ of the patients were predisposed to respiratory failure and ventilator assistance. Clinically important leakage of the anastomosis or esophageal substitute occurred in $6 \%$ of the patients but was healed by drainage alone in all patients. Cardiovascular events, thrombosis and embolic complications were also observed. Five patients died in hospital following the transhiatal procedure (9.1\%). Two of the five patients were older than 80 years and four of the patients had symptomatic comorbidity. No surgeryrelated deaths occurred following the transthoracic procedure resulting in an overall in-hospital mortality rate of $5.7 \%$. The median stay in the intensive care unit beyond the recovery period was 1 day and the hospital stay of patients with a transthoracic or transhiatal procedure was 17 days (range 10-114) and 15 days (range 3-256), respectively.

The average number of retrieved lymph nodes from the specimens was 15.6 (95\% CI: $13.5-17.6)$ and varied between 1 and 49. After transthoracic or transhiatal esophagectomy, the mean number of examined lymph nodes was 17.8 (95\% CI: 14.6-21.1) and 14.2 (11.5-16.9), respectively $(P=0.089)$. Patients with lymph node metastases had 1 through 19 involved lymph nodes, and the mean number of involved lymph nodes was 5.9 (95\% CI: 3.5-8.2) after transthoracic and 4.1 (2.9-5.3) after transhiatal esophagectomy $(P=0.184)$.

The depths of tumor invasion and the frequency of lymph node metastases were similar in the two treatment groups. Approximately $60 \%$ of the patients presented with a pT3 tumor or lymph node metastases (Table 3). Lymph node metastases were identified in patients with pT1 tumors (15\%) although the frequency was significantly less than among patients with a pT2 $(59 \%)$ or pT3 tumor $(74 \%)(P<0.02)$ (Table 4$)$.

The survival rates after transthoracic or transhiatal esophagectomy were respectively $31.2 \%$ and $27.8 \%$ by 5 years, and $21.3 \%$ and $16.6 \%$ by 10 years, and the median time of survival after transthoracic or transhiatal esophagectomy was 20.5 months (95\% CI: 10.4-57.6) and 16.4 months (95\% CI: 10.6-28.7), respectively. The treatment groups' similar mortality ratio, indicate that there is no survival benefit from transthoracic esophagectomy when compared with survival rates of transhiatal esophagectomy $(\mathrm{RMR}=1.14, P=0.63)$. Figure 1 and Table 5 illustrate and summarize the statistics in detail.

The analyses of treatment specific survival rates allowed for pooling of patients in order to study disease and impact of patient specific factors on survival. The overall survival rates of patients after esophagectomy were $25 \%$ and $20.8 \%$ by 5 and 10 years, respectively with a SMR of 6.3 when compared to the general population (Figure 2a) and the overall median time of survival was 16.4 (95\% CI: 12.5-28.7) months. 
Table 2 Surgical events and complications of surgery for adenocarcinoma of the esophagus

\begin{tabular}{|c|c|c|c|c|}
\hline & $\begin{array}{c}\text { All resections } \\
n=88(\%)\end{array}$ & $\begin{array}{c}\text { Transthoracic } \\
n=33(\%)\end{array}$ & $\begin{array}{c}\text { Transhiatal } \\
n=55(\%)\end{array}$ & $P$ \\
\hline Surgical events & $11(13)$ & $6(18)$ & $5(9)$ & 0.318 \\
\hline - Recurrent nerve injury & $5(6)$ & $3(9)$ & $2(4)$ & \\
\hline - Chylous leakage & $4(5)$ & $2(6)$ & $2(4)$ & \\
\hline - Tracheal injury & $2(2)$ & $1(3)$ & $1(2)$ & \\
\hline Splenectomy & $16(18)$ & $4(12)$ & $12(22)$ & 0.197 \\
\hline \multicolumn{5}{|l|}{ Postoperative events } \\
\hline Pulmonary failure & $12(14)$ & $6(18)$ & $6(11)$ & 0.354 \\
\hline Cardiovascular events & $5(6)$ & 0 & $5(9)$ & 0.152 \\
\hline Thromboembolism & $6(7)$ & $4(12)$ & $2(3)$ & 0.192 \\
\hline Anastomose leakage & $5(6)$ & $2(6)$ & $3(6)$ & 0.905 \\
\hline Infectious complications & $38(43)$ & $18(55)$ & $20(36)$ & 0.121 \\
\hline - Pneumonia & $30(34)$ & $13(39)$ & $17(32)$ & \\
\hline - Incision & $4(5)$ & $3(9)$ & $1(2)$ & \\
\hline - Abdominal abscess & $3(3)$ & $1(3)$ & $2(4)$ & \\
\hline - Lung abscess & $1(1)$ & $1(3)$ & 0 & \\
\hline Other / minor complications & $12(14)$ & $6(18)$ & $6(11)$ & 0.354 \\
\hline Patients with complications & $49(56)$ & $21(64)$ & $28(51)$ & 0.275 \\
\hline Intensive care, days (range) & $1(0-69)$ & $1(0-69)$ & $1(0-65)$ & $0.457^{\mathrm{a}}$ \\
\hline Hospital stay, days (range) & $16(3-256)$ & $17(10-114)$ & $15(3-256)$ & $0.086^{a}$ \\
\hline Mortality (in-hospital) & $5(5.7)$ & 0 & $5(9.1)$ & 0.152 \\
\hline
\end{tabular}

${ }^{a}$ Mann-Whitney $\mathrm{U}$ test otherwise statistics with Fisher's exact test.

In the absence of lymph node metastases, the survival rates by 5 and 10 years were $52.6 \%$ and $48.9 \%$ (Figure 2c), whereas the survival rate was reduced to $7.5 \%$ and $3.8 \%$ when lymph nodes metastases were identified (Figure 2e) (RMR 2.22, $P=0.007$, Table 5). Different levels of lymph node involvement were statistically not associated with differences in survival rates of transthoracic or transhiatal esophagectomy in this series of patients. The median times of survival for patients with or without lymph node metastases were 10.7 months (95\% CI: 7.9-14.9) and 74.0 months (95\% CI: 17.5-166.4), respectively.

Table 3 Tumor and lymph node stages among patients with a transthoracic or transhiatal esophagectomy for adenocarcinoma of the esophagus

\begin{tabular}{lcccc}
\hline & Total (\%) & $\begin{array}{c}\text { Transthoracic } \\
\boldsymbol{n}=\mathbf{3 3}(\%)\end{array}$ & $\begin{array}{c}\text { Transhiatal } \\
\boldsymbol{n = 5 5}(\%)\end{array}$ & $\boldsymbol{P}$ \\
\hline PT 1 & $13(15)$ & $3(9)$ & $10(18)$ & \\
PT 2 & $22(25)$ & $12(36)$ & $10(18)$ & 0.125 \\
PT 3 & $53(60)$ & $18(55)$ & $35(64)$ & \\
pN0 & $34(39)$ & $13(39)$ & $21(38)$ & 1.0 \\
pN1 & $54(61)$ & $20(61)$ & $34(62)$ & \\
\hline
\end{tabular}

Stages based on microscopy of the specimens. Statistics by Fisher's exact test.
The effect of tumor invasion on survival is presented in Figure 2b,d,f. Patients with a pT1 tumor were few and their survival rate was not statistically different to that of the general population (SMR $=1.7,95 \% \mathrm{CI}: 0.7-4.1)$ and a median survival time was never reached for this stage of tumor invasion during a maximal follow up of 196 months. Median time of survival for patients with a pT2 tumor was 30.4 (95\% CI: 9.0-142) months. The median survival time of patients with a pT3 tumor was 14 (9.2-16.4) months, and the relative mortality of patients with a pT3-stage was statistically increased, when compared with patients with pT1-stage $(P=0.024)$.

Age was a prognostic factor by the time of operation expressed by a relative mortality of 0.43 per 10 years,

Table 4 The frequency of lymph node metastases according to the tumors depth of invasion into the esophagus wall

\begin{tabular}{lcccc}
\hline & \multicolumn{4}{c}{ All resections } \\
T-stage & no & pN 0 (\%) & pN 1 (\%) & $\boldsymbol{P}$ \\
\hline pT 1 & 13 & $11(85)$ & $2(15) *$ & $P<0.02$ \\
PT 2 & 22 & $9(41)$ & $13(59)$ & \\
pT 3 & 53 & $14(26)$ & $39(74)$ & \\
\hline
\end{tabular}

${ }^{*} P<0.02$, pT1 different from pT2 and pT3 by Fisher's exact test. 

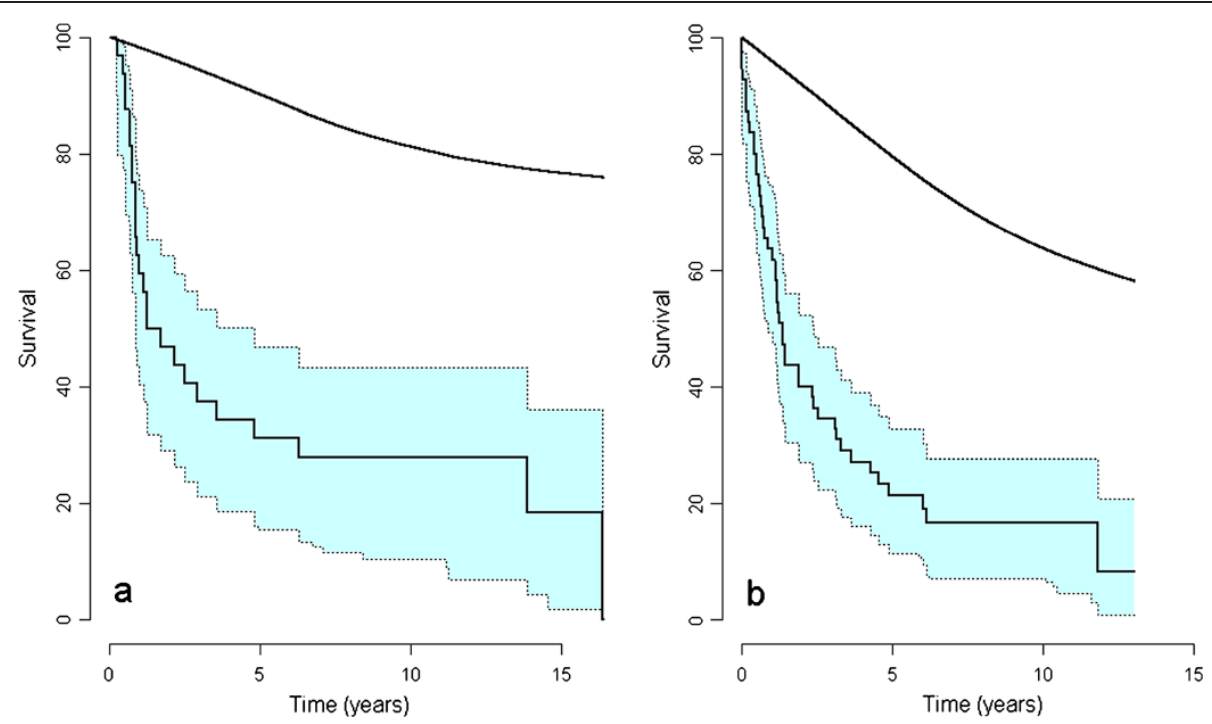

Figure 1 The observed mortality rate with $95 \%$ confidence interval of patients with adenocarcinoma of the esophagus after (a) transthoracic- or (b) transhiatal esophagectomy. The corresponding mortality rate of the general population with the same composition of age, gender, and year of birth as the treatment group is presented as the uppermost single plot in each panel.

which implies a decrease in relative mortality for the patients (with respect to the population) of $57 \%$ per 10 years of increasing age. The standardized mortality rate was especially pronounced for patients with an age below 70 years $(\mathrm{SMR}=2.4)$ and 60 years $(\mathrm{SMR}=7.6)$ (Table 5). Patients over the age of 80 years did not reach a 5-year survival and their median survival time was 6 months (95\% CI: 3.3-8.8).
The patients' gender was not a prognostic factor for relative mortality in this study.

\section{Discussion}

This study shows that survival of more than ten years can be expected after esophagectomy for adenocarcinoma of the esophagus without adjuvant or neoadjuvant radiochemotherapy. Increasing depth of tumor invasion

Table 5 Survival rates according to operative procedure, lymph node metastases and primary tumor infiltration in patients treated for adenocarcinoma of the esophagus

\begin{tabular}{|c|c|c|c|c|c|c|c|c|c|c|c|}
\hline & $\mathrm{N}$ & Observed deaths & $S_{0}(5)$ & $95 \% \mathrm{Cl}$ & $S_{O}(10)$ & $95 \% \mathrm{Cl}$ & SMR & $95 \% \mathrm{Cl}$ & RMR & $95 \% \mathrm{Cl}$ & $P$ value \\
\hline Total & 88 & 72 & 25.0 & $16.2-34.4$ & 20.8 & $11.8-29.9$ & 6.3 & $5.0-8.0$ & & & \\
\hline Transthoracic & 33 & 26 & 31.2 & $15.5-46.8$ & 27.8 & $10.4-43.2$ & 6.2 & $4.2-9.1$ & 1 & ref & ref \\
\hline Transhiatal & 55 & 46 & 21.3 & $11.5-32.7$ & 16.6 & $7.2-27.6$ & 6.4 & $4.8-8.5$ & 1.14 & $0.67-1.96$ & 0.63 \\
\hline $\mathrm{pNO}$ & 34 & 20 & 52.6 & $34.0-67.5$ & 48.9 & $27.2-64.2$ & 2.8 & $1.8-4.3$ & 1 & ref & ref \\
\hline $\mathrm{pN1}$ & 54 & 52 & 7.5 & $2.2-15.9$ & 3.8 & $0.5-10.0$ & 12.3 & $9.4-16.2$ & 2.22 & $1.24-3.98$ & 0.007 \\
\hline pT1 & 13 & 5 & 68.4 & $35.6-86.2$ & 57.0 & $14.9-78.9$ & 1.7 & $0.7-4.1$ & 1 & ref & ref \\
\hline pT2 & 22 & 18 & 38.1 & $18.0-57.0$ & 33.3 & $11.8-52.2$ & 3.8 & $2.4-6.0$ & 1.47 & $0.49-4.48$ & 0.50 \\
\hline pT3 & 53 & 49 & 9.4 & $2.9-18.5$ & 7.1 & $1.9-15.5$ & 13.4 & $10.1-17.7$ & 3.22 & $1.16-8.91$ & 0.024 \\
\hline Male & 75 & 62 & 24.1 & $15.0-34.2$ & 19.2 & $10.1-28.9$ & 6.7 & $5.2-8.6$ & 1 & ref & ref \\
\hline Female & 13 & 10 & 30.8 & $6.8-53.7$ & 30.8 & $3.9-53.7$ & 4.7 & $2.5-8.7$ & 1.84 & $0.88-3.86$ & 0.11 \\
\hline$<60$ & 28 & 23 & 25.0 & $9.9-41.0$ & 20.8 & $6.7-36.5$ & 7.9 & $5.3-11.9$ & & & \\
\hline $60-69$ & 23 & 17 & 27.3 & $10.8-45.4$ & 27.3 & $6.2-45.4$ & 2.4 & $1.5-3.9$ & & & \\
\hline $70-79$ & 28 & 23 & 32.1 & $15.1-48.7$ & 21.4 & $7.3-38.3$ & 1.5 & $0.98-2.2$ & & & \\
\hline $80+$ & 9 & 9 & 0 & - & 0 & - & 1.3 & $0.7-2.4$ & & & \\
\hline Age/10 years & & & & & & & & & 0.43 & $0.35-0.52$ & $<0.001$ \\
\hline
\end{tabular}

$\mathrm{S}_{\mathrm{O}}(5)$ and $\mathrm{S}_{\mathrm{O}}(10)$ are the observed survivals in percent (Kaplan-Meier) at 5 and 10 years respectively with $95 \% \mathrm{Cl}$. The SMR is the observed mortality (Obs) divided by the mortality in the general population with the same composition of age, gender, and year of birth (Expected number of deaths, Exp) as that of the study group. The RMRs compare the SMRs for different levels of the variables RMR $\mathrm{R}_{\text {Gender }}=\mathrm{SMR}_{\mathrm{Female}} / \mathrm{SMR}_{\text {Male }}$, but adjusted for the other factors in the table. 

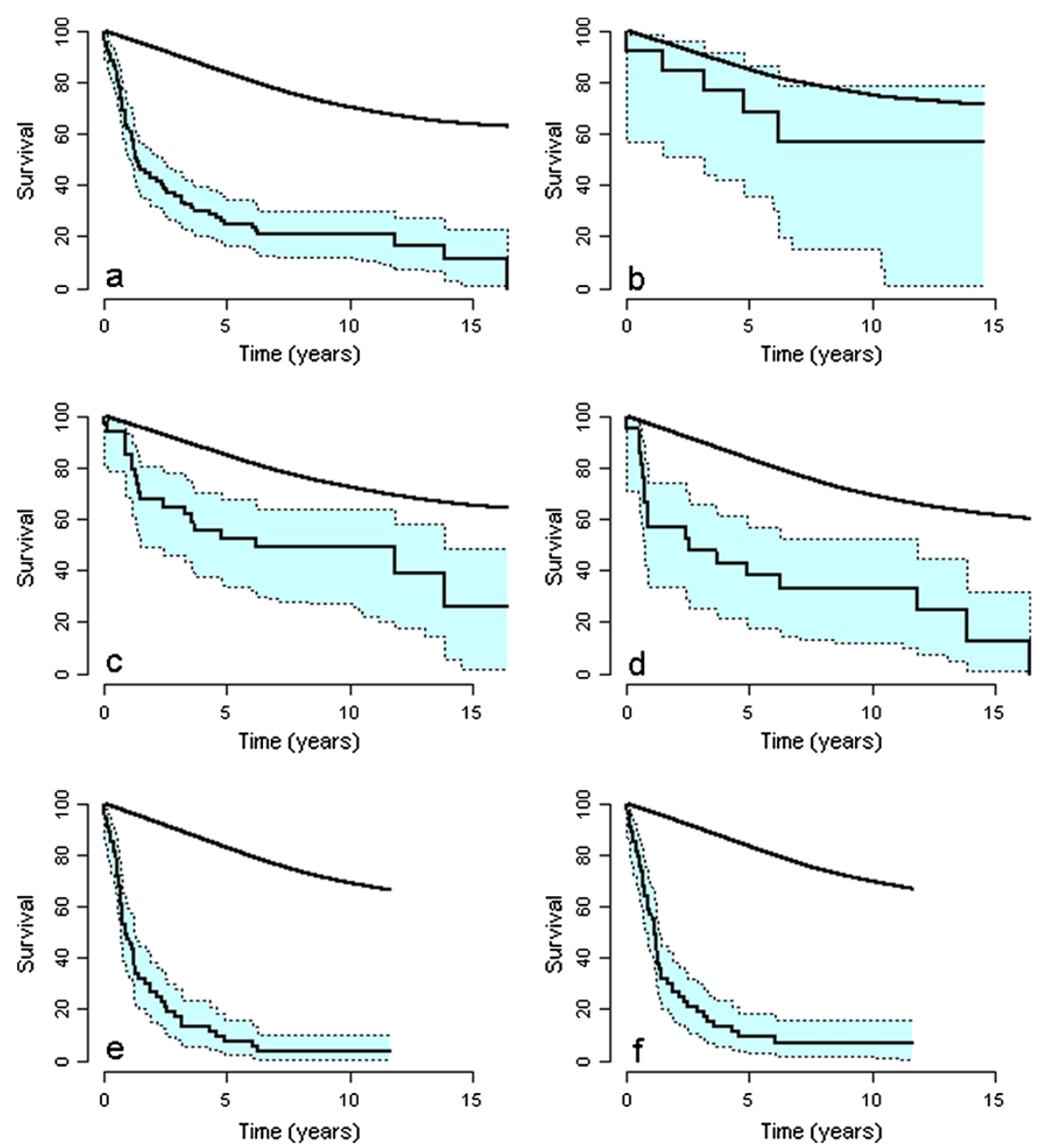

Figure 2 The observed mortality rate with $95 \%$ confidence interval of patients with adenocarcinoma of the esophagus. The panels illustrate the mortality rate of all patients after esophagectomy (a), patients without lymph node involvement (c), patients with lymph node metastases (e), patients with pT1 tumors (b), patients with pT2 tumors (d), and patients with pT3 tumors (f). The corresponding mortality rate of the general population with the same composition of age, gender, and year of birth as the treatment group is presented in each panel.

and the presence of lymph node metastases reduce life expectancy significantly, whereas the surgical approach is less likely to affect the survival rate.

\section{Method}

The statistical methods used in this article adjust for mortality rates from the general population. The analyses hence mimic a study with a (random) control group from the population. By doing this we adjust for the fact that mortality increases with age in the population (and also for the patients) and is higher for males than females. Thus the variables adjusted for in the analyses are also adjusted for the mortality found in the general population [23]. Although the patients are represented in the mortality from the general population, the age-adjusted incidence rates of esophagus carcinoma in
Norway is low $(2.8-3.4 / 100,000)$ [22], and the amount of contribution to the mortality found in the general population is therefore low.

\section{Morbidity/mortality}

Complications are generally observed in $33-71 \%$ of patients after esophagectomy $[4,9,26]$, and it is debated whether complication rates are related to type of surgical procedure. Complication rates were statistically not related to surgical procedure in this study. Similar overall morbidity rates of transthoracic (53.5\%) and transhiatal (49.3\%) esophagectomies are reported by Connors et al. [27] after analyzing 17,395 esophagectomies. This is supported by Rentz et al. [28] in an analysis of 562 transthoracic and 383 transhiatal resections with a morbidity rate of $47 \%$ and 49\%, respectively. Only a randomized 
comparison of transthoracic and transhiatal approaches reveal more chylous leakage, prolonged ventilator support, longer intensive care and hospital stay after transthoracic esophageal resection [9].

The overall mortality rate of $5.7 \%$ in this series of patients is similar to that of other reports (2.4-6\%) $[4,9,26]$ and higher mortality rates of $8.4-10 \%$ or $8.9-9.9 \%$ are seen after transthoracic or transhiatal esophagectomy $[27,28]$. The in-hospital deaths (Table 2 ) were closely associated with advanced age and comorbidity which is more frequent among patients subject to transhiatal esophagectomy in this series of patients (Table 1).

\section{Overall survival}

The overall SMR of 6.3 relative to the death rate of the general Norwegian population emphasizes the serious prognosis and the vast potential for treatment improvement among patients with adenocarcinoma of the esophagus.

Extensive transthoracic en bloc esophagectomy with a five-year survival rate of 52\% [4] is generally considered more efficient and superior to transhiatal esophagectomy with survival rate of $31 \%$ [5]. Comparative studies support transthoracic en block resection as a superior procedure to transhiatal resections for all stages of the disease including advanced tumors with limited lymph node metastases [6,7]. Our study shows that any apparent survival benefit of transthoracic over transhiatal surgery is eroded when results are adjusted for year of birth, age, gender, and stage of disease (Table 5). This is in concordance with the Dutch trial that adheres to the Siewert's classification and includes both type I and type II cardiac cancers $[9,10,16]$. The Dutch trial show a superiority of transthoracic en bloc resection for type I adenocarcinoma, whereas transthoracic and transhiatal esophagectomy obtain similar survival rates for type II carcinomas [10]. However, the distinction between tumors close to the GE junction is often blurry and lymph node dissection during transhiatal esophagectomy is very different from that of transthoracic esophagectomy in the Dutch study, whereas in our series of patients the lymph node dissection in the abdomen and at the cardia is identical in the two treatment groups.

Moreover, it may be too ambitious to expect any beneficial effect of extended loco regional treatment on patient survival rate when the recurrence rate outside the treatment area is very high. Recurrences after esophagectomy for adenocarcinoma of the esophagus are frequent and approximately $39-56 \%$ of recurrences are related to hematogenous dissemination of tumor cells [29-31] of which $37.5 \%$ of recurrences occur in the liver, $25 \%$ in bones, $17.5 \%$ in lung and $11 \%$ in the brain $[29,32]$. The high rates of recurrences outside the dissection area may very well override and extinguish any possible beneficial effects of lymph node dissection by transthoracic or transhiatal esophagectomy on patient survival.

\section{Survival by stage}

The main predictors of outcome in this study, depths of tumor invasion (pT-stage) and lymph node status (pNstage) (Figure 2, Table 5), are known predictors of local recurrences and distant metastases within one or two years of the operation $[4,10,29,30]$. Location of lymph node metastases is not predictive of recurrence or survival and therefore not considered in this study [4]. Increasing the number of dissected lymph nodes favorably influences survival rates [33-35]. The varying number of examined lymph nodes in this study may affect precision in staging of patients and distort some of the results in this study by stage migration [35]. In order to improve staging lymph nodes are now harvested from the specimens by the operating surgeon.

Transhiatal esophagectomy is often reported with a more limited lymph node dissection than transthoracic esophagectomy $[9,35]$. In this study lymph node dissection during transthoracic and transhiatal esophagectomy is identical in the abdomen and at the cardia. Any apparent numeric difference between the two treatment groups is probably related to the additionally dissected lymph nodes in the upper mediastinum during transthoracic esophagectomy.

The complexity of lymph node metastases and outcome by surgical approaches are shown in subanalyses of the Dutch randomized trial [10]. Survival rates of extended transthoracic esophagectomy is superior to that of limited transhiatal esophagectomy when a moderate number of lymph nodes are present (1-8 involved notes), but the survival rates are similar when lymph nodes are uninvolved or massively involved ( $>8$ involved notes) [10]. Similarly Johansson et al. [7] show that patients undergoing transthoracic en bloc resection for T3 N1 adenocarcinoma of the distal esophagus had a survival benefit over those treated with transhiatal resection when less than 9 involved lymph nodes are present. Although the lethality among patients with lymph node metastases is high (Figure 2, Table 5), extended mediastinal and abdominal dissection to remove possibly involved nodes is supported by several authors $[7,31,32,36]$.

The depth of tumor invasion is strongly associated with the risk of lymph node metastases (Table 4). Only $15 \%$ of patients with a pT1 tumor are at risk of having lymph node metastases. Intramucosal carcinomas are rarely associated with lymph node metastases ( $8 \%$ when confined in lamina propria) (20\% when invading the mucosal muscular layer), and limited or even vagal sparing resections are justified in these patients [37]. Locally 
advanced tumors (pT3) are closely associated with metastases (Table 4) and require more extended surgical options.

It is important to realize that the number of patients eligible for curative resections is limited (60\%) and the frequency of regional metastases is high (Tables 3, 4). A tailored treatment strategy therefore requires an ambitious preoperative work up to identify patients with possible metastases. Preoperative loco regional staging of esophageal cancer with EUS provides excellent $\mathrm{T}$ staging accuracy and the accuracy for $\mathrm{N}$ staging compares well with positron emission tomography and CT [38], EUS is also associated with improved survival stratification in patients with esophageal adenocarcinoma [39]. Although the total number of involved lymph nodes is not readily available for preoperative stratification of surgical treatment, the coherence between $\mathrm{T}$ stage and $\mathrm{N}$ stage seen in this study (Table 4) supports a strategy based on a thorough preoperative evaluation of $\mathrm{T}$ stage. We therefore favor $\mathrm{T}$ stage and $\mathrm{N}$ stage rather than aggregated stages in order to establish a clinical fundament for decision making and comparison in clinical practice.

Patients with adenocarcinoma in the esophagus at an age of less than 60 years have the highest SMRs due to the longer life expectancy of their corresponding matched controls in the background population (Table 5). These patients are therefore likely to benefit the most from multimodal neoadjuvant or adjuvant therapy. The shorter life expectancy of the aged background population explains less SMRs of aged patients. Patients of 80 years or more in this study are prone to in-hospital mortality and a limited length of survival following esophagectomy. This group of patients may therefore benefit from a more palliative approach and esophagectomy may be limited to a selected group of well-functioning patients of 80 years or more.

\section{Material}

The exclusion of patients with residual tumor (R1 or 2) violates the intention to treat principle, but reduces the number of confounding factors in the comparison of transthoracic and transhiatal esophagectomy. Moreover, high-resolution CT, 8F-Fluorodeoxyglucose-positron emission tomography (FDG-PET) and EUS during preoperative work up are now also likely to identify most of these patients prior to surgery $[18,40,41]$. The allocation of patients to transthoracic or transhiatal esophagectomy is not random and patients with a transhiatal esophagectomy are somewhat older than patients with transthoracic esophagectomy. However, stages of disease (Table 3) are similarly represented in the two treatment groups and the demographic selection biases are adjusted for by statistical methods. Results are therefore considered valid.

\section{Implications}

This study supports both transthoracic and transhiatal esophagectomy as valid options with similar survival and morbidity rates among patients operated without neoadjuvant radiochemotherapy. However, the transthoracic approach is associated with superior survival rates for type I adenocarcinoma in larger series and should probably be the method of choice for patients that can sustain the risk of more morbidity and a longer hospital stay $[9,10]$.

The distinctions in Siewert's classification are not recognized in later classifications [16,17]. We therefore advocate transthoracic esophagectomy to patients with adenocarcinoma at the distal esophagus that cannot be visualized at the cardia with a looped endoscope.

The work up of these patients is complex and despite an increasing incidence of adenocarcinoma at the distal esophagus and cardia, care for these patients should be confined to a limited number of centers [42].

\section{Conclusion}

Esophagectomy for adenocarcinoma of the esophagus may convey long-term survival of more than ten years without addition of adjuvant therapy. The prognoses are however closely associated with stage of disease and less influenced by surgical approach. The SMR of 6.3 emphasizes a vast potential for improvement of treatment, and strategies for the future should probably involve new multimodal therapy and detection of disease at an early stage.

\section{Competing interests}

The authors declare that they have no competing interests.

\section{Authors' contributions}

$\mathrm{KKO}, \mathrm{KS}$, and $\mathrm{AV}$ cooperated in the conception and design of the study and in the collection of the data. ODL validated all pathology reports and SAL assisted in data analysis and interpretation of data. KO drafted the manuscript. All authors read and approved the final manuscript.

\section{Author details}

${ }^{1}$ Department of Surgery, Haukeland University Hospital, Bergen 5021, Norway. ${ }^{2}$ Department of Surgical Sciences, University of Bergen, Bergen, Norway. ${ }^{3}$ Uni Health, Uni Research, Christies Street 13, Bergen 5015, Norway. ${ }^{4}$ Department of Pathology, The Gade Institute, Section of Pathology, University of Bergen, Haukeland University Hospital, Bergen, Norway.

Received: 3 January 2012 Accepted: 7 May 2012

Published: 30 June 2012

\section{References}

1. Pohl H, Welch HG: The role of overdiagnosis and reclassification in the marked increase of esophageal adenocarcinoma incidence. J Natl Cancer Inst 2005, 97:142-146.

2. DeMeester SR: Epidemiology and biology of esophageal cancer. Gastrointest Cancer Res 2009, 3:S2-S5.

3. Hulscher JB, Tijssen JG, Obertop H, van Lanschot JJ: Transthoracic versus transhiatal resection for carcinoma of the esophagus: a meta-analysis. Ann Thorac Surg 2001, 72:306-313.

4. Hagen JA, DeMeester SR, Peters JH, Chandrasoma P, DeMeester TR: Curative resection for esophageal adenocarcinoma: analysis of 100 en bloc esophagectomies. Ann Surg 2001, 234:520-530. 
5. Orringer MB, Marshall B, Chang AC, Lee J, Pickens A, Lau CL: Two thousand transhiatal esophagectomies: changing trends, lessons learned. Ann Surg 2007, 246:363-372.

6. Portale G, Hagen JA, Peters JH, Chan LS, DeMeester SR, Gandamihardja TA, DeMeester TR: Modern 5-year survival of resectable esophageal adenocarcinoma: single institution experience with 263 patients. J Am Coll Surg 2006, 202:588-596.

7. Johansson J, DeMeester TR, Hagen JA, DeMeester SR, Peters JH, Oberg S, Bremner CG: En bloc vs transhiatal esophagectomy for stage T3 N1 adenocarcinoma of the distal esophagus. Arch Surg 2004, 139:627-631.

8. Gockel I, Heckhoff S, Messow CM, Kneist W, Junginger T: Transhiatal and transthoracic resection in adenocarcinoma of the esophagus: does the operative approach have an influence on the long-term prognosis? World J Surg Oncol 2005, 3:40.

9. Hulscher JB, van Sandick JW, de Boer AG, Wijnhoven BP, Tijssen JG, Fockens $P$, Stalmeier PF, ten Kate FJ, van Dekken H, Obertop H, et al: Extended transthoracic resection compared with limited transhiatal resection for adenocarcinoma of the esophagus. N Engl J Med 2002, 347:1662-1669.

10. Omloo JM, Lagarde SM, Hulscher JB, Reitsma JB, Fockens P, van Dekken H, ten Kate FJ, Obertop H, Tilanus HW, van Lanschot JJ: Extended transthoracic resection compared with limited transhiatal resection for adenocarcinoma of the mid/distal esophagus: five-year survival of a randomized clinical trial. Ann Surg 2007, 246:992-1000.

11. Mariette C, Castel B, Toursel H, Fabre S, Balon JM, Triboulet JP: Surgical management of and long-term survival after adenocarcinoma of the cardia. Br J Surg 2002, 89:1156-1163.

12. Rudiger SJ, Feith M, Werner M, Stein HJ: Adenocarcinoma of the esophagogastric junction: results of surgical therapy based on anatomical/topographic classification in 1,002 consecutive patients. Ann Surg 2000, 232:353-361.

13. Stein HJ, Feith M, Mueller J, Werner M, Siewert JR: Limited resection for early adenocarcinoma in Barrett's esophagus. Ann Surg 2000, 232:733-742.

14. Johansson J, Djerf P, Oberg S, Zilling T, von Holstein CS, Johnsson F, Walther B: Two different surgical approaches in the treatment of adenocarcinoma at the gastroesophageal junction. World J Surg 2008, 32:1013-1020

15. Lazzarino Al, Nagpal K, Bottle A, Faiz O, Moorthy K, Aylin P: Open versus minimally invasive esophagectomy: trends of utilization and associated outcomes in England. Ann Surg 2010, 252:292-298.

16. Siewert JR, Stein HJ: Classification of adenocarcinoma of the oesophagogastric junction. Br J Surg 1998, 85:1457-1459.

17. UICC: TNM Classification of Malignant Tumours. New York: Wiley-Blackwell; 2009.

18. Nesje LB, Svanes K, Viste A, Laerum OD, Odegaard S: Comparison of a linear miniature ultrasound probe and a radial-scanning echoendoscope in TN staging of esophageal cancer. Scand J Gastroenterol 2000, 35:997-1002.

19. Orringer MB, Sloan H: Esophagectomy without thoracotomy. J Thorac Cardiovasc Surg 1978, 76:643-654.

20. Akiyama $H$, Tsurumaru M, Kawamura T, Ono Y: Principles of surgical treatment for carcinoma of the esophagus: analysis of lymph node involvement. Ann Surg 1981, 194:438-446.

21. UICC: TNM Classification of Malignant Tumours. New York: Wiley-Liss; 2002.

22. Cancer Registry of Norway: Cancer in Norway 2008 - Cancer incidence, mortality, survival and prevalence in Norway. Oslo: Cancer Registry of Norway; 2009.

23. Lie SA, Lie RT, Svanes C: Expected survival compared with survival of peptic ulcer patients. Stat Med 1998, 17:1189-1199.

24. Andersen PK, Vaeth M: Simple parametric and nonparametric models for excess and relative mortality. Biometrics 1989, 45:523-535.

25. Andersen PK, Borch-Johnsen K, Deckert T, Green A, Hougaard P, Keiding N, Kreiner S: A Cox regression model for the relative mortality and its application to diabetes mellitus survival data. Biometrics 1985, 41:921-932.

26. Ito H, Clancy TE, Osteen RT, Swanson RS, Bueno R, Sugarbaker DJ, Ashley SW, Zinner MJ, Whang EE: Adenocarcinoma of the gastric cardia: what is the optimal surgical approach? J Am Coll Surg 2004, 199:880-886.

27. Connors RC, Reuben BC, Neumayer LA, Bull DA: Comparing outcomes after transthoracic and transhiatal esophagectomy: a 5-year prospective cohort of 17,395 patients. J Am Coll Surg 2007, 205:735-740.

28. Rentz J, Bull D, Harpole D, Bailey S, Neumayer L, Pappas T, Krasnicka B, Henderson W, Daley J, Khuri S: Transthoracic versus transhiatal esophagectomy: a prospective study of 945 patients. J Thorac Cardiovasc Surg 2003, 125:1114-1120.

29. Wayman J, Bennett MK, Raimes SA, Griffin SM: The pattern of recurrence of adenocarcinoma of the oesophago-gastric junction. Br J Cancer 2002, 86:1223-1229

30. de Manzoni G, Pedrazzani C, Pasini F, Durante E, Gabbani M, Grandinetti A, Guglielmi A, Griso C, Cordiano C: Pattern of recurrence after surgery in adenocarcinoma of the gastro-oesophageal junction. Eur J Surg Oncol 2003, 29:506-510.

31. Clark GW, Peters JH, Ireland AP, Ehsan A, Hagen JA, Kiyabu MT, Bremner CG, DeMeester TR: Nodal metastasis and sites of recurrence after en bloc esophagectomy for adenocarcinoma. Ann Thorac Surg 1994, 58:646-653.

32. Hulscher JB, van Sandick JW, Tijssen JG, Obertop H, van Lanschot JJ: The recurrence pattern of esophageal carcinoma after transhiatal resection. J Am Coll Surg 2000, 191:143-148.

33. Greenstein AJ, Litle VR, Swanson SJ, Divino CM, Packer S, Wisnivesky JP: Effect of the number of lymph nodes sampled on postoperative survival of lymph node-negative esophageal cancer. Cancer 2008, 112:1239-1246.

34. Altorki NK, Zhou XK, Stiles B, Port JL, Paul S, Lee PC, Mazumdar M: Total number of resected lymph nodes predicts survival in esophageal cancer. Ann Surg 2008, 248:221-226.

35. Bogoevski D, Onken F, Koenig A, Kaifi JT, Schurr P, Sauter G, Izbicki JR, Yekebas EF: Is it time for a new TNM classification in esophageal carcinoma? Ann Surg 2008, 247:633-641.

36. Nigro JJ, DeMeester SR, Hagen JA, DeMeester TR, Peters JH, Kiyabu M, Campos GM, Oberg S, Gastal O, Crookes PF, et al: Node status in transmural esophageal adenocarcinoma and outcome after en bloc esophagectomy. J Thorac Cardiovasc Surg 1999, 117:960-968.

37. Oh DS, Hagen JA, Chandrasoma PT, Dunst CM, DeMeester SR, Alavi M, Bremner CG, Lipham J, Rizzetto C, Cote R, et al: Clinical biology and surgical therapy of intramucosal adenocarcinoma of the esophagus. J Am Coll Surg 2006, 203:152-161.

38. Choi J, Kim SG, Kim JS, Jung HC, Song IS: Comparison of endoscopic ultrasonography (EUS), positron emission tomography (PET), and computed tomography (CT) in the preoperative locoregional staging of resectable esophageal cancer. Surg Endosc 2010, 24:1380-1386.

39. Chen J, Xu R, Hunt GC, Krinsky ML, Savides TJ: Influence of the number of malignant regional lymph nodes detected by endoscopic ultrasonography on survival stratification in esophageal adenocarcinoma. Clin Gastroenterol Hepatol 2006, 4:573-579.

40. Westerterp $M$, van Westreenen HL, Sloof GW, Plukker JT, van Lanschot J]: Role of positron emission tomography in the (re-)staging of oesophageal cancer. Scand J Gastroenterol 2006, 243:116-122.

41. Heeren PA, Jager PL, Bongaerts F, van Dekken H, Sluiter W, Plukker JT: Detection of distant metastases in esophageal cancer with (18)F-FDG PET. J Nucl Med 2004, 45:980-987.

42. Funk LM, Gawande AA, Semel ME, Lipsitz SR, Berry WR, Zinner MJ, Jha AK Esophagectomy outcomes at low-volume hospitals: the association between systems characteristics and mortality. Ann Surg 2011, 253:912-917.

doi:10.1186/1477-7819-10-130

Cite this article as: Ovrebo et al.: Long-term survival from adenocarcinoma of the esophagus after transthoracic and transhiatal esophagectomy. World Journal of Surgical Oncology 2012 10:130

\section{Submit your next manuscript to BioMed Central and take full advantage of:}

- Convenient online submission

- Thorough peer review

- No space constraints or color figure charges

- Immediate publication on acceptance

- Inclusion in PubMed, CAS, Scopus and Google Scholar

- Research which is freely available for redistribution 